Research Article

\title{
Large-Scale and Refined Green Space Identification-Based Sustainable Urban Renewal Mode Assessment
}

\author{
Rong Guo $\mathbb{D}^{1},{ }^{1}$ Xiaoya Song $\mathbb{D}^{1},{ }^{1}$ Peiran $\mathrm{Li}^{2}{ }^{2}$ Guangming $\mathrm{Wu},{ }^{2}$ and Zhiling Guo ${ }^{2}$ \\ ${ }^{1}$ Key Laboratory of Cold Region Urban and Rural Human Settlement Environment Science and Technology, \\ Ministry of Industry and Information Technology, School of Architecture, Harbin Institute of Technology, Harbin 150006, China \\ ${ }^{2}$ Center for Spatial Information Science, The University of Tokyo, Kashiwa 277-8568, Japan
}

Correspondence should be addressed to Rong Guo; hitarchit.gr@gmail.com and Xiaoya Song; xy.song8989@gmail.com

Received 31 July 2020; Revised 20 August 2020; Accepted 24 August 2020; Published 30 September 2020

Guest Editor: Jie Yan

Copyright (C) 2020 Rong Guo et al. This is an open access article distributed under the Creative Commons Attribution License, which permits unrestricted use, distribution, and reproduction in any medium, provided the original work is properly cited.

Urban sustainable renewal has received extensive attention in a wide range of fields, including urban planning, urban management, energy management, and transportation. Given that environmental resource conservation is critical to urban sustainability renewal, this study highlighted the imbalance among green space, urban development, and transportation accessibility. Here, a novel node-place-green model is presented to measure sustainable urban development; meanwhile, deep learning is utilized to identify and extract the green space to measure the environmental index. Based on the generated node, place, and green value, urban developing status could be classified into nine modes for further analysis of transportation, urban function, and ecological construction. The experimental results of Harbin reveal the feasibility of the proposed method in providing specific guidelines for urban planning and policies on sustainable development.

\section{Introduction}

A multitude of efforts towards low-carbon urban development foster concentration strategies around improving built environment, which is closely related to vehicular emissions [1]. Recently, a multitude of efforts towards sustainable performance assessment are focusing on strategies around improving urban renewal, which is closely related to transportation emissions [2, 3]. For instance, a study demonstrated that the sustainability research board reported that the conservation of resources and the environment gains the highest weight of $29 \%$ in the sustainable urban renewal model [4]. Also, a more recent study showed that improving neighborhood design leads to a $75 \%$ reduction in energy use and GHG emissions [5]. Besides, some extensive literatures explored the strategies of reducing GHG emissions by improving the green space during urban renewal [6]. Hence, combining urban renewal with urban green space is critical to sustainable development [7]. During urban renewal, the imbalance in urban resource allocation is inevitable and is mainly reflected when developing transportation infrastructure and the corresponding urban functional facilities [8].
The cities in the developing countries renovate things that have long been supported by land finance and marked by space excessive consumption; the following consequential environmental and social issues as follows are in need of being urgently addressed: low concentration degree of functions [9], lack of vitality [10], and the public space being unsuitable for the demand of development $[11,12]$. Additionally, an array of functional contradictions like the fading nature ecological system are primarily attributed to the urban huge inner stock space as well as pretty low efficiency of land use [13]. At present, mainly featuring the partial sections used for the planned regions of renovation projects, the ways through which these old cities renovate and implement schemes remain destitute of an all-round research on the urban systematical level [14]. During the renovation, typically, developers only pass the benchmark of various technique standards and compress the public service facilities and opened spaces $[15,16]$; they also raise the volume of development at their will and maximize their profits $[17,18]$. As a result, this leads to an array of the Gordian knots, including excessive intensity of old city development, 
destitution of public service facilities, uncoordinated environmental landscape, and unbalanced urban functions [19]. Old city renovation, namely, a crucial method to revitalize the urban stock land, holds the key to raising land intensity degree and boosting the metabolism of old urban functions [20]. Therefore, it is impressive to study and explore the problem of how to strike a balance between transportation and land use in the stock development to revitalize the city and coordinate with the urban sustainable redevelopment goals [21].

Regarding urban sustainable redevelopment with balance, the node-place model has always been one of the hottest topics. The node-place model establishes a methodological framework, the maximum value for studying the coordinated development between land use and transportation in the adjacent regions [22]. This model makes a hypothesis that there exists a sustainable and positive feedback mechanism between the "node value" relying on the transportation services and the "place value" relying on the land use. The balance between the "node value" and the "place value" of a certain area can be considered as an important reference for evaluating whether this area possesses the potentials of urban construction. Five development states are distinguished by the node-place model (Figure 1). Each situation reflects its development stage and state in terms of the balance between urban function and traffic. The "balanced" state means the coordinated development of transportation and urban functions. The "dependent" state at the bottom of the curve shows that both the transportation construction and urban functions are relatively weak. Therefore, external factors need to intervene to maintain and promote the development of this area. As opposed to the "dependent" state, both transportation and urban functions have been developed to the utmost intensity on the "stress" state, which means further redevelopment may cause larger conflicts. The remaining two are the "unbalanced" state. On this state, the development only focuses on one aspect (transportation or urban function). A large number of articles attempted to utilize the node-place model from the perspective of station classification [23], transportation network assessment [24], sustainable redevelopment [25], accessibility analysis [26], and planning policy [27]. The node-place model is used to determine the form and extent of redevelopment of the Tokyo station regions [28]. Vale compared related literatures and combined land use, transportation, and walkability conditions to evaluate and classify station regions of Lisbon [29]. Considering the complexity of urban problems, the node-place model has gradually begun to be extended to evaluate complex situations [30]. The design index was included in the evaluation system and applied to location-related city regulations and policies [31]. In this paper, the refined evaluation indexes of urban green space are incorporated into the node-place models to widen the decisionmaking dimension of sustainable urban renewal mode. Combination of transportation, land use, and ecological construction could identify the development stage of sustainable urban renewal more scientifically.

As for the measurement of urban green space, instead of the time-consuming survey and fieldwork, with the rapid development of remote sensing [32] as well as computer vision techniques [33], the automatic

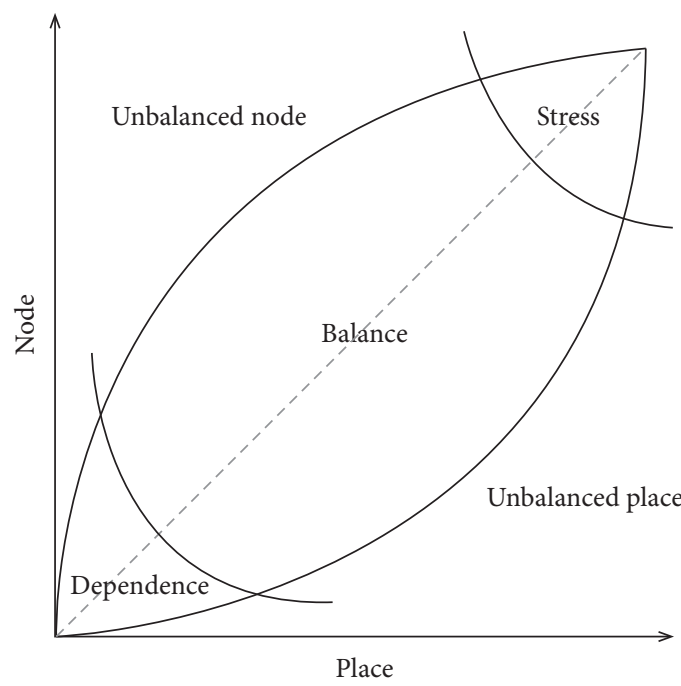

Figure 1: The node-place model by Bertolini [22].

extraction of the green space from remote sensing imagery based on machine learning methods [34] has emerged as a promising alternative strategy. In terms of remote sensing imagery for vegetation, although the normalized difference vegetation index (NDVI) [35] has been widely utilized in several empirical studies [36-38], the limitation of resolution and availability inevitably hinders its deployment in urban regions. Thanks to the dramatically increasing availability of new large-scale remote sensing data sources $[39,40]$, the ever-expanding high-resolution dataset with ground truth can be utilized for training the urban vegetation extraction model. On the other hand, the deep learning methods, here referred to as deep convolution neural networks [41], have shown the tremendous capability in pattern recognition tasks. Recent deep learning based studies for land feature extraction including vegetation segmentation $[42,43]$, which outperformed conventional machine learning based methods such as support vector machine (SVM) [44] and neural network (NN) [32], reveal its potential in different urban vegetation extraction tasks.

In this research, we chose the main urban districts of Harbin as our study area. First, we use U-Net [45] to identify and extract the green space, mainly including low vegetation and trees in Harbin; the ratio of vegetation to the region reveals and measures the environmental index of the corresponding region. Second, we expanded the node-place model, using those green indicators as the third dimension to jointly measure the state of urban construction. Finally, according to the evaluation results of the node-place-green model, we classified the sustainable renewal models in Harbin and proposed a targeted renewal strategy for each type of characteristic.

The main contributions of this study are fourfold:

We expanded the node-place model's dimensions combining transportation, urban function, and ecological construction to analyze the sustainable urban development mode 
We utilized the U-Net model to identify urban vegetation and trees on a large scale in satellite images, which ensures the refinement of urban feature recognition

We analyzed the sustainable urban renewal model using the identified green space, which dynamically monitors the sustainable renewal status

We identified the state of the urban construction in Harbin and proposed a future sustainable development model for transportation, urban function, and ecological construction

The remainder of this paper is organized as follows. In Section 2, the workflow of the proposed method is illustrated, where the details of metrics as well as the algorithms are also presented. Then, the study area and data source are introduced. After that, experimental results and discussion are demonstrated in Section 3. Finally, the conclusions are drawn in Section 4.

\section{Materials and Methods}

2.1. Study Area and Data. In this research, we choose the main urban districts of Harbin as our study area, endeavouring to identify which regions have the potential for further sustainable renewal. As the northernmost subprovincial city in China, Harbin is located in the Northeast Plain. In Harbin, the urban construction land is $458 \mathrm{~km}^{2}$, including the old town of $298 \mathrm{~km}^{2}$. With the development of the city, various contradictions in the old town have become more prominent. The high urban density, traffic congestion, environmental pollution, and insufficient green space have led to a decline in the overall functions of main urban districts and increased difficulty in urban renewal. Harbin is also a typical winter city with a long and cold winter. Therefore, there is urgency to improve the green space and enhance the quality of the outdoor environment. In order to analyze the place value in each region, in this research, we collect land use status drawn by GIS in basic regions at the town-and-street level in the overall land use plan of the main urban area of Harbin and PoI data with 27 features. As for urban green classification, the ISPRS benchmark [39] and Google Earth (GE) RGB imagery are selected to perform the training and testing data, respectively. Considering the resolution and color space difference between training and testing datasets, the preprocessing, including downscaling and color normalization, is applied.

2.2. U-Net for Urban Vegetation Area Extraction. As one of the state-of-the-art models for deep learning based image semantic segmentation, U-Net has been successfully applied to perform different tasks with high accuracy and efficiency. Considering the characteristics of U-Net, which could perform pixel-to-pixel and end-to-end mapping from input to output while enabling precise localization for the vegetation segmentation results, in this study, we propose to adopt U-Net as a representative segmentation model for urban vegetation area extraction.
Concretely, the convolution operation performs element-wise multiplication via kernels. In U-Net, it can be formulated as follows:

$$
z=\sum_{i=1}^{h_{f}} \sum_{j=1}^{w_{f}} \sum_{d=1}^{c_{l}} \Theta_{i, j, s, d^{\prime}} \times x_{i, j, d}+b_{d^{\prime}}
$$

where $h_{f}$ and $w_{f}$ represent the height and width of the kernel $\Theta, c_{l}$ is the number of channels for input $x$ in layer $l$, and $b$ in shape $1 \times 1 \times 1 \times d^{\prime}$ denotes the bias.

Subsequently, Leaky ReLU [46] and batch-normalization [47] are used to generate the hypothesis from $z$ and reduce internal covariate shift, respectively. The final classification of either vegetation or nonvegetation is predicted by using softmax function [48].

2.3. Node-Place-Green Model. The node-place model is applied to balance the transportations and urban functions of the railway network and the railway station area [22]. Considering the similarities between the transportation system and urban construction, the node-place model is gradually being applied to the evaluation of large-scale urban development. The subway and bus system in Harbin exhibit the same transportation functions as the railway network and are densely distributed in urban regions. Therefore, the establishment principles and theories of node-location model are also applicable to the research objects of this article.

Urban green space refers to the vegetation system that exists in the urban area in natural or artificial form, including trees and low shrubs. Urban green space is prone to regulate the urban ecosystem, protect the environment, and provide residents with a good place to relax. Therefore, the advantages of the green space system in the construction of sustainable urban development are constantly highlighted. This paper broadens the dimensions of the node-place model and incorporates the evaluation indicators of the green space system into the evaluation system (Table 1).

The place value, node value, and green value, are respectively, $Z$-transformed, and the processed result $\left(x_{m}^{\prime}\right.$, $y_{m}^{\prime}$, and $\left.g_{m}^{\prime}\right)$ represents the place value, node value, and green value of each basic region. Then, the three are used as three-dimensional coordinates to make a scatter plot, $y$, which can be denoted by equation (2). In the end, according to the division of balance, imbalance, dependence, and pressure, the location projected by the basic unit is judged as nine sustainable urban renewal modes. Each of these nine modes can be represented in a cube, as illustrated in Figure 2:

$$
A_{m}=\Phi\left(x_{m}^{\prime}, y_{m}^{\prime}, g_{m}^{\prime}\right)
$$

where $A_{m}$ denotes the coordinated development status of transportation, urban functions, and green space of region $m$, and $x_{m}^{\prime}, y_{m}^{\prime}$, and $g_{m}^{\prime}$, respectively, denote the place value, node value, and green value of region $m$. 
TABLE 1: Indicators in node-place-green model.

\begin{tabular}{|c|c|}
\hline Description & Calculation of the indices \\
\hline \multicolumn{2}{|l|}{ Node index } \\
\hline Number of directions served by subway & $y_{1}=$ number of subway services offered at station \\
\hline Daily frequency of services by subway & $y_{2}=$ number of subways departing from station on working day \\
\hline $\begin{array}{l}\text { Number of directions served by other public } \\
\text { transport }\end{array}$ & $y_{3}=$ number of public trfansport services offered at station \\
\hline $\begin{array}{l}\text { Daily frequency of services by other public } \\
\text { transport }\end{array}$ & $y_{4}=$ number of buses, trams, and underground trains departing from station on working \\
\hline Proximity to CBD & $y_{5}=$ travel time to the $\mathrm{CBD}$ \\
\hline \multicolumn{2}{|l|}{ Place index } \\
\hline $\begin{array}{l}\text { Restaurant, entertainment, and hotel within } 15 \\
\text { minutes' walking distance }\end{array}$ & $\begin{array}{c}x_{1}=\text { number of POIs within } 15 \text { minutes' walking distance in restaurant, entertainment, } \\
\text { and hotel }\end{array}$ \\
\hline $\begin{array}{l}\text { Industry and distribution within } 15 \text { minutes' } \\
\text { walking distance }\end{array}$ & $\begin{array}{l}x_{2}=\text { number of POIs within } 15 \text { minutes' walking distance in transport distribution } \\
\text { centers and warehouses, private warehouses, gas stations, factories, and crafts }\end{array}$ \\
\hline $\begin{array}{l}\text { Commerce, finance, and real estate within } 15 \\
\text { minutes' walking distance }\end{array}$ & $\begin{array}{c}x_{3}=\text { number of POIs within } 15 \text { minutes' walking distance in commercial corporations, } \\
\text { banks, real estate agency, communication, newspaper, and broadcasting }\end{array}$ \\
\hline $\begin{array}{l}\text { Education, health, and culture within } 15 \\
\text { minutes' walking distance }\end{array}$ & $\begin{array}{c}x_{4}=\text { number of POIs within } 15 \text { minutes' walking distance in hospitals, social insurance, } \\
\text { social welfare, all kinds of schools, research institute, skill classroom, and government } \\
\text { office }\end{array}$ \\
\hline $\begin{array}{l}\text { Administration and services within } 15 \text { minutes' } \\
\text { walking distance }\end{array}$ & $\begin{array}{c}x_{5}=\text { number of POIs within } 15 \text { minutes' walking distance in travel agencies, amusement } \\
\text { parks, gardens, public bathhouses, and temples }\end{array}$ \\
\hline Land use mixture & $\begin{array}{c}\left.x_{6}=1-((a-b) / d)-(a-c) / d\right) / 2 \\
a=\max (x 1, x 2, x 3, x 4, x 5) \\
b=\min (x 1, x 2, x 3, x 4, x 5) \\
c=\operatorname{mean}(x 1, x 2, x 3, x 4, x 5) \\
d=\sum_{x 1}+x 2+x 3+x 4+x 5\end{array}$ \\
\hline
\end{tabular}

Green index

Low vegetation cover

$g_{1}=$ the ratio of low vegetation area to building area

Tree cover $g_{2}=$ the ratio of tree area to building area

\section{Results and Discussion}

3.1. Place Value. First, the node-place-green model is utilized to calculate the place value of Harbin. The place value reflects the present status of public service facilities in urban functions. The larger the place value, the higher the completeness of urban functions in the region, which means living more conveniently. Deducing from the box plots (Figure 3), it can be stated that the place value of Harbin is mainly distributed between 0.05 and 0.38 , and the median and mean value are lower than the node value and green value. In addition, it is demonstrated that there is a large gap in the place value in various regions of Harbin, and the overall development in urban function lags behind that of transportation and green space. The spatial distribution of Harbin place value is illustrated in Figure 4. On the whole, the Harbin place value presents a single-center structure. The place value gradually decreases with the old city as the center. Moreover, although individual residential regions in the outer urban regions have higher place value, the outer urban regions are generally lower than the old urban regions. In terms of central regions, regions with high place value are mainly concentrated in Nangang District and Daoli District, and they are distributed in multiple centers. The multicenter structure is consistent with the distribution of Harbin's main business districts. According to the distribution of the "three old" regions in Harbin, it can be stated that the urban functions in old southern Harbin are still relatively weak.
From the perspective of the spatial distribution of the place value, the urban renewal in the north, south, and west of the main urban area has potential.

3.2. Node Value. Second, the node value of Harbin is calculated. Node value reflects public transportation accessibility. The larger the node value, the more developed the public transportation, that is, the higher the regional accessibility. As shown in Figure 3, the Harbin node value is mainly distributed between 0.35 and 0.45 , and the median and mean value are the highest of the three. More specifically, the development of public transportation in various regions of Harbin is relatively balanced, and the overall development level is higher than that of urban functions and green space. The spatial distribution of node value in Harbin is demonstrated in Figure 5. The node value is generally more scattered than the place value, showing one linear and multicenter structure. The node values in the southern part of the Songhua River are all higher than those in the northern part. In addition, the high value is more concentratedly distributed at the junction of the north and south urban regions. Deducing from the result, it can be stated that the urban transportation infrastructure construction focuses on the initial stage of strengthening the coordinated development of the northern and southern cities. In terms of the southern urban area, vertical transportation development is relatively mature and has excellent accessibility. 


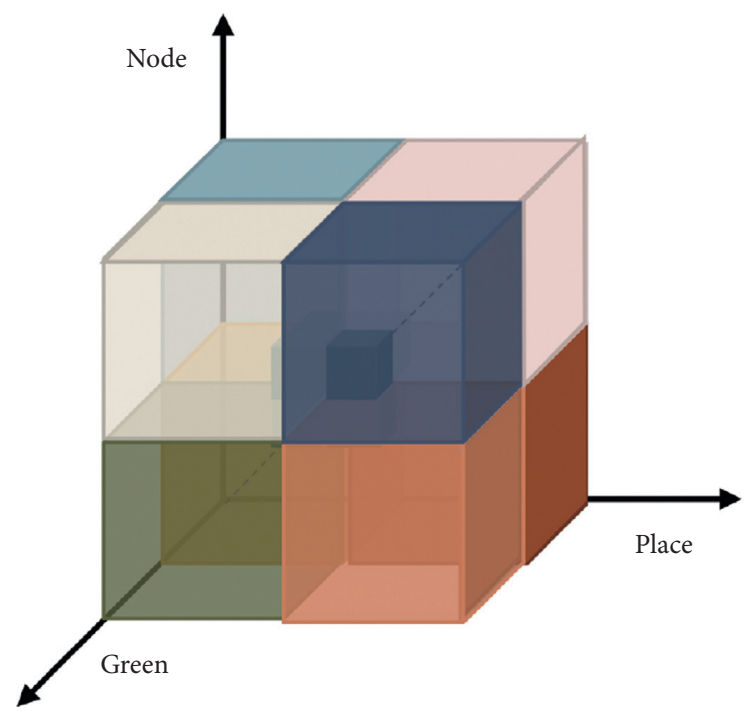

Ecological restoration

Enhancement to node with greenbelt

Enhancement to place with greenbelt

Green reinforcement

Green concerned redevelopment

Environmental-based enhancement to node

Environmental-based enhancement to place

Refined renewal

Problem-oriented renewal

FIgurE 2: The node-place-green model and the nine sustainable urban renewal modes.

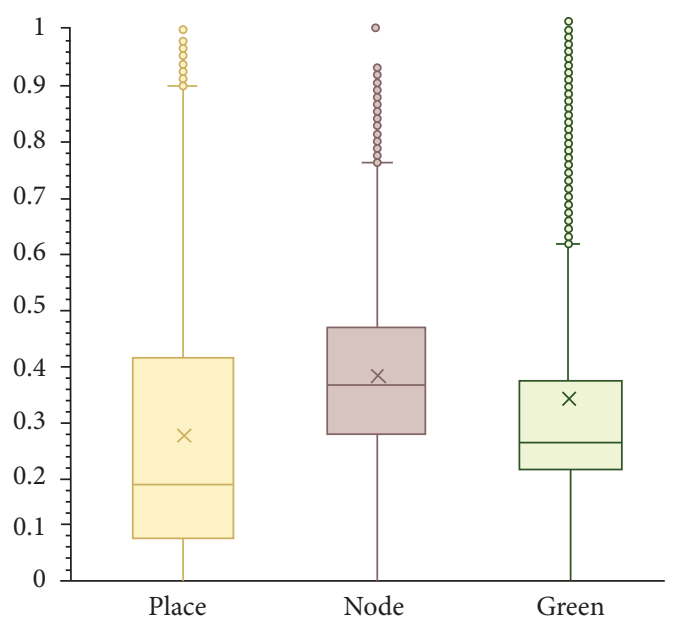

FIGURE 3: Box plots of the normalization of place, node, and green in Harbin.
From the perspective of node value, the northern parts of Harbin's main urban area have more significant potential for renewal.

3.3. Green Value. We use deep learning to identify the urban green space (low vegetation and trees) in Harbin. The ratio of vegetation to the region reveals and measures the environmental index. The larger the green value, the higher the green vegetation coverage in the region. As illustrated in Figure 3, most of the green value is distributed between 0.18 and 0.35 , and the distribution is relatively concentrated. It shows that the gap in various regions of Harbin in green value is small, but the overall level is low. Harbin's green value is shown schematically in Figure 6. Opposed to the place value and node value, the green value distribution has no visible structural characteristics. Some regions on the edge of the city have high green value, and most of these regions are undeveloped farmland. The overall green value of the urban area is low, and there is no large-scale concentration. The green value in the old urban area with high place value and traffic value is generally low, mostly below 0.2 , and this area has a high demand for greening.

3.4. Determination of Sustainable Urban Renewal Mode. As analyzed above, place value, node value, and green value, respectively, reveal the current status of urban construction in terms of urban function, transportation, and environment. These three comprehensively reflect the current situation of the city. For a comprehensive discussion on strategies for sustainable urban renewal, we performed a cluster analysis to identify the development status of the regions in Harbin. Based on the transformed place value, node value, and green value, nine unique clusters are interpreted in Table 2, and the corresponding structure is illustrated in Figure 7. The detailed analysis is as follows.

3.4.1. Mode 1: Ecological Restoration. Mode 1 comprises low place value, node value, and green value. That is, the region is relatively weak in transportation, urban functions, and the environment. 58\% of regions in Harbin were identified in such a group.

This mode is named "ecological restoration" because these regions have a poor environment under low-intensity urban development. Except for the central area, such regions are widely distributed in Harbin's main urban area, which reveals the low overall development intensity and the lack of green space system. Due to geographical barriers, in the process of urban renewal, the development of the northern Songhua River has been lagging behind that of the southern part in the upgrading of transportation infrastructure or the improvement of urban public service facilities. Moreover, in the southern Songhua River, the development intensity of Qunli New District and residential quarters' density has gradually increased in recent years. Nevertheless, the result reveals the same problems exposed in the above two types of development states. Under the direction of sustainable renewal, regardless of the previous development status, the 


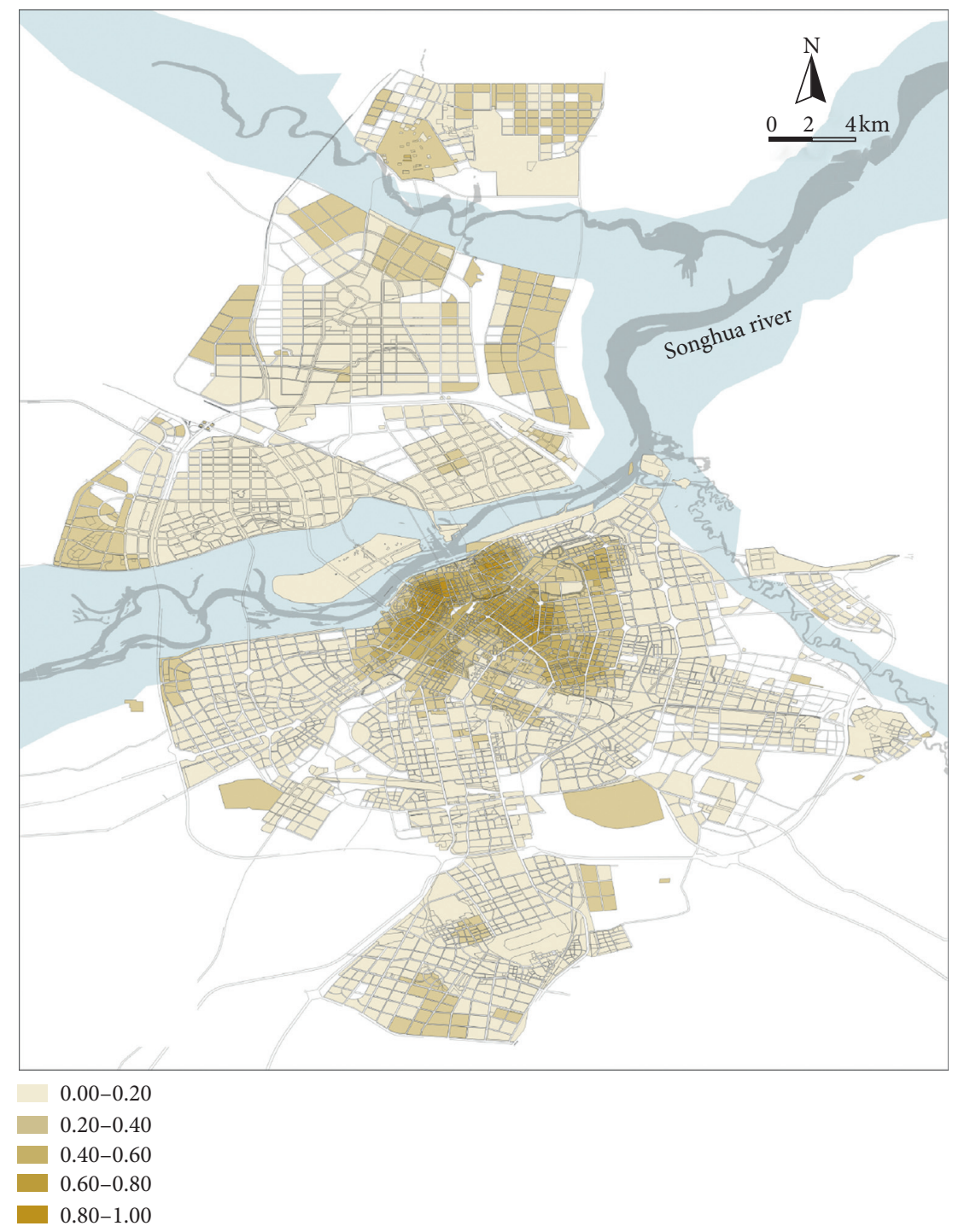

Figure 4: Place value of the regions in Harbin.

region in this mode should focus on improving the green space system.

\subsubsection{Mode 2: Enhancement to Node with Greenbelt.} 9.1\% of Harbin regions are identified with high place value and a low node value and green value. More specifically, the regions are relatively well developed in urban functions and weak in transportation and the environment.

Mode 2 is named "enhancement to node with greenbelt" because these regions have high-intensity urban functions but lack traffic accessibility and green space. These regions are concentrated in the old city of central Harbin. There are largescale and high-density old buildings in these regions, with excellent urban historical and cultural characteristics. However, in the process of urban renewal, due to the obsolete road system and high building density, the development is still concentrated on the commercial development of existing buildings. This result reveals that the current development intensity of the area in terms of urban functions is tending towards perfection.
Consequently, it should focus on the redevelopment of public transportation and the recombination of green space and urban public space.

3.4.3. Mode 3: Enhancement to Place with Greenbelt. This mode comprises high node value and low place value and green value. Besides, the region is relatively well developed in urban transportation and weak in function and environment. The regions under this mode are identified to account for $9.2 \%$ of Harbin.

This mode is called "enhancement to place with greenbelt" because these regions have developed public transportation systems, but urban public service facilities and green space systems still need to be improved. Such regions are distributed in the central area and the south of Harbin. With the construction of the subway connecting the north and south of Harbin, the renewal of the area around the subway is gradually accelerating. As illustrated in Figure 7 , with the development of two subway lines in the 


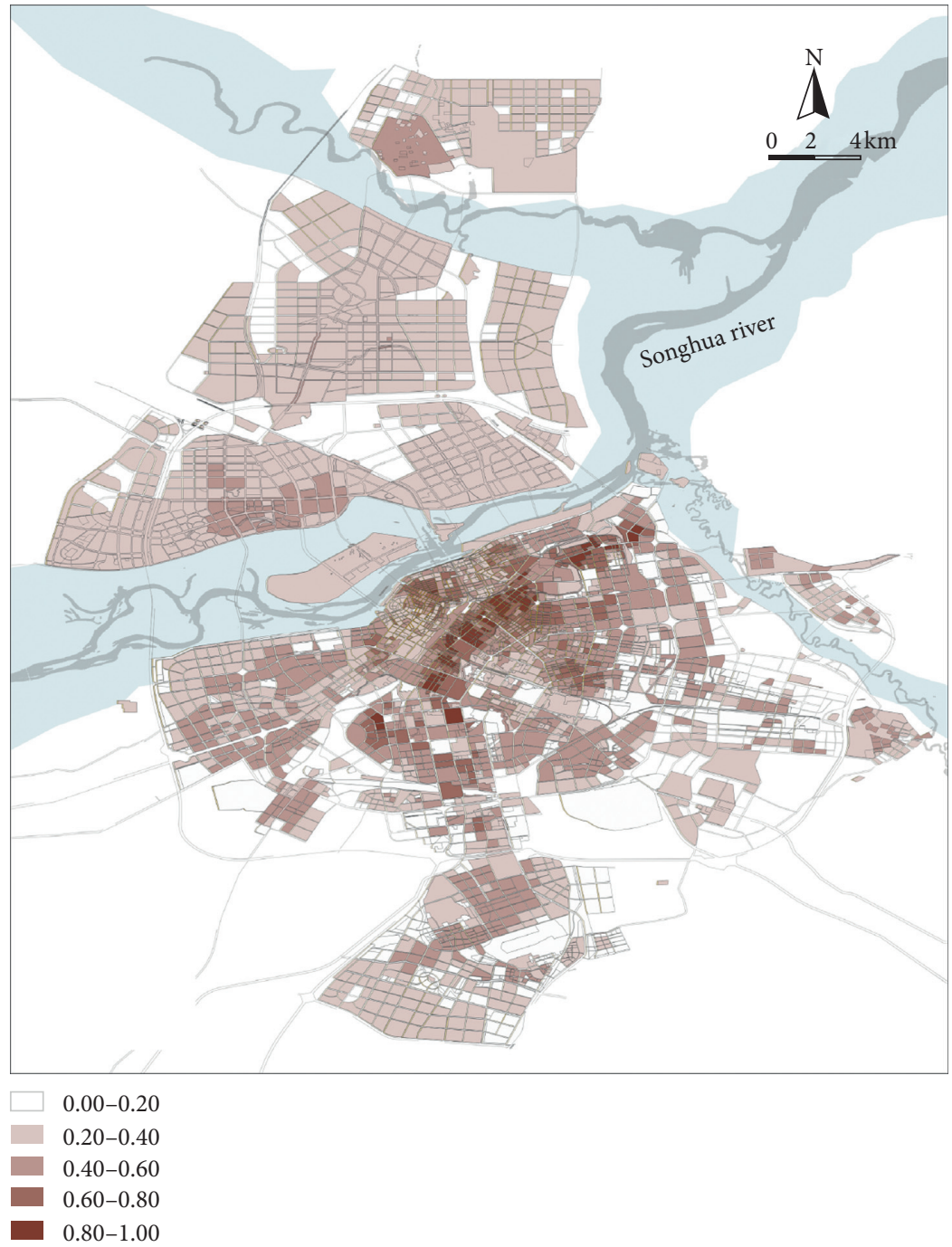

FIgURE 5: Node value of the regions in Harbin.

central area, the accessibility of these regions has been well improved. Additionally, urban functions cannot meet the current traffic conditions. Moreover, in the construction of transportation infrastructure, it is rarely combined with green space. It reveals that, in the future sustainable urban renewal, the redevelopment of urban commercial and public service facilities should be appropriately increased, and urban traffic nodes should be combined with relevant green space for systematic construction.

3.4.4. Mode 4: Green Reinforcement. 6.5\% of regions in Harbin were identified with high node value and place value and low green value. The regions under mode 4 are relatively well developed in urban functions and transportation and are relatively weak in the environment.

This mode is named "green reinforcement" because these regions have complete urban public service facilities and a developed public transportation system with fewer low vegetation and trees and weak green space systems. Such regions are distributed in parts of the old city and commercial districts in the city center. The development of transportation and urban functions is relatively balanced, and the intensity is relatively high. However, the area and amount of green space are small. Except for parks, these regions have a small green area and low vegetation and tree coverage. This result reveals that the future renewal of the area should slow down the development of traffic and urban functions, focusing on the maintenance of existing green space and the expansion of public space.

3.4.5. Mode 5: Green Concerned Redevelopment. This mode incorporates low node value and space value and high green value. These regions are still in the infancy in urban functions and transportation, but the vegetation coverage rate is high. The regions under this mode are identified to account for $15.6 \%$ of Harbin.

This mode is named "green concerned redevelopment" because, compared with the development of transportation and urban functions, the vegetation coverage in this mode is higher, and the green environment is well. Such regions are 


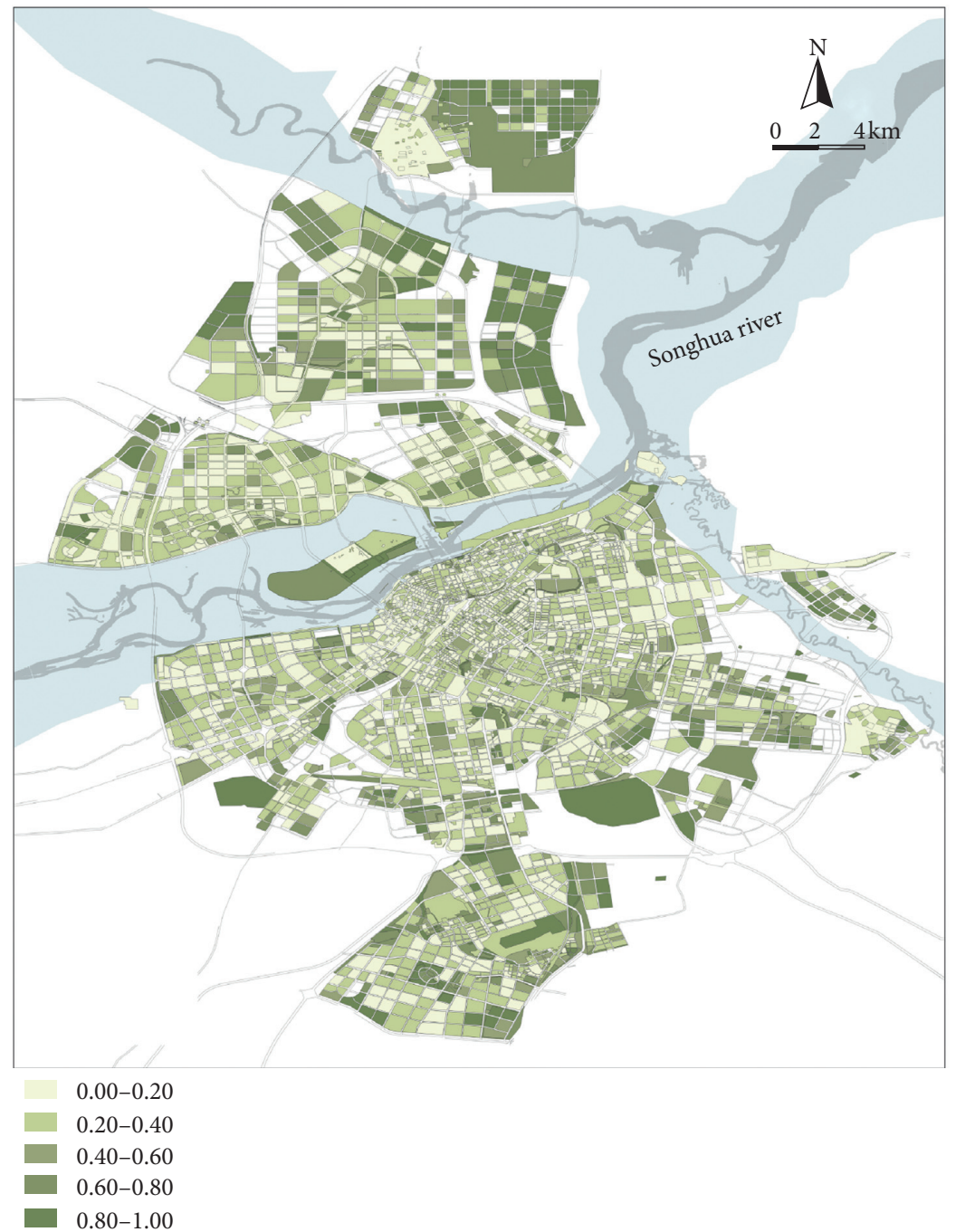

Figure 6: Green value of the regions in Harbin.

TABLE 2: Explanation for the sustainable urban renewal modes.

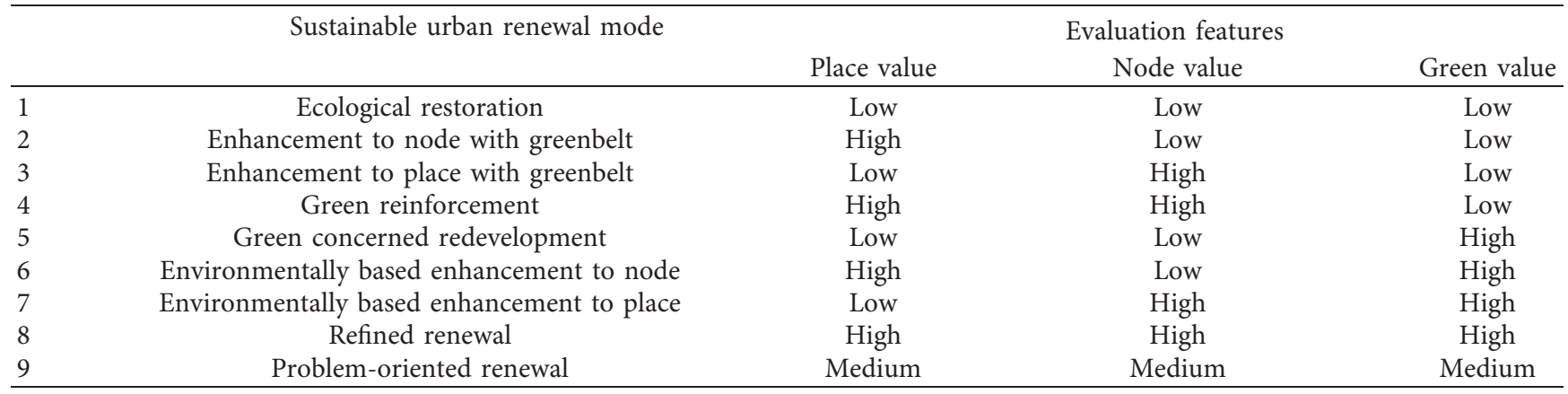

scattered in various parts of Harbin, the outer area is large and concentrated, and the central area is small and scattered. Most of these regions distributed in the periphery of the urban area are undeveloped farmland. Additionally, most of these regions are urban green space. This reveals that the future renewal should focus on small-intensity redevelopment based on protecting the existing green environment.
3.4.6. Mode 6: Environmental-Based Enhancement to Node. $0.9 \%$ of the regions in Harbin are identified with high place value and green value and low node value. This indicates that the regions are well constructed in urban functions and green space, but the traffic accessibility is weak. This mode is named "environmentally based enhancement to node" because the urban functions and greening environment 


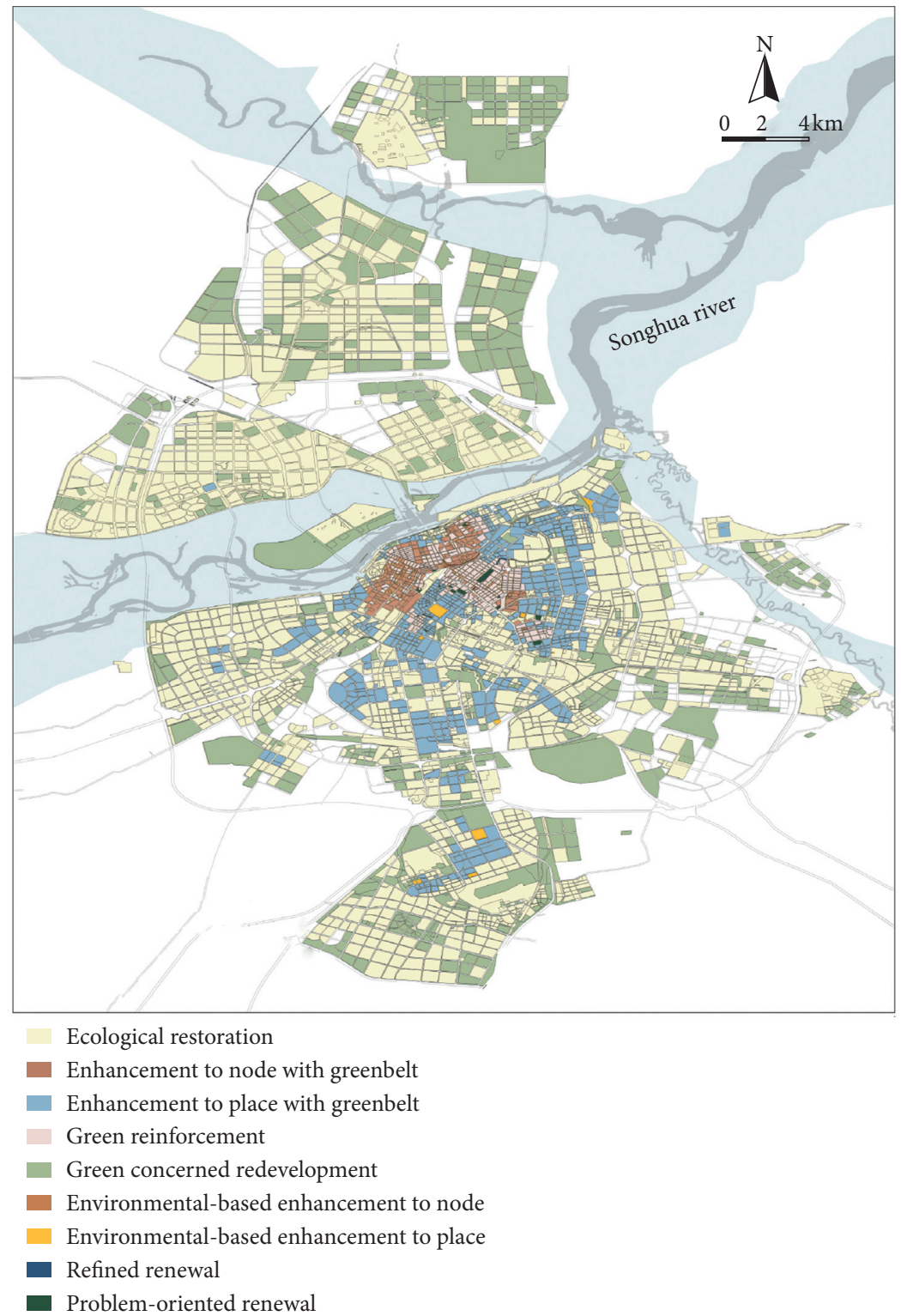

Figure 7: Sustainable urban renewal modes of Harbin.

construction are coordinated and perfect. Nevertheless, transportation is relatively inconvenient. Such regions are scattered in the center of Harbin, corresponding to urban green spaces with little traffic. Moreover, they are adjacent to Harbin's commercial district and have a high potential for redevelopment. Therefore, future renewal should focus on increasing public transport connectivity while maintaining the existing environment.

3.4.7. Mode 7: Environmental-Based Enhancement to Place. Mode 7 comprises high node value and green value and low place value. These regions are identified to account for $0.2 \%$ of Harbin and are well constructed in urban traffic and greening with weak urban function. This mode is named "environmentally based enhancement to place" because the urban public transportation in these regions is highly accessible and the green environment is good, but the urban functions are insufficient. Such regions are scattered in the city center, corresponding to several urban parks and parks with single functions. These regions are generally adjacent to "enhancement to place with greenbelt"; so future updates should be coordinated with the redevelopment of "enhancement to place with greenbelt" and endeavor to protect the existing environment.

3.4.8. Mode 8: Refined Renewal. Mode 8 contains high node value, place value, and green value. More specifically, the development of these areas has higher intensity and better perfection in terms of urban functions, transportation, and green space. These regions are identified to account for $0.17 \%$ of Harbin. This mode is called "refined renewal" because, in Harbin, these regions have concentrated and 
complete development in the above three aspects. Such regions are scattered in central urban regions, and the renewal should focus on refinement and quality.

3.4.9. Mode 9: Problem-Oriented Renewal. $0.69 \%$ of regions in Harbin are identified with medium node value, place value, and green value. Additionally, the development of these regions is coordinated in terms of urban functions, transportation, and greening. Also, there is still a certain amount of development space. Given the relative balance in the above three aspects, the renewal of this type of the regions should focus on the current demands within the region, that is, to adjust the focus of development based on the problem to maintain the current equilibrium state.

In brief, based on the place value, node value, and green value, nine sustainable urban renewal modes are identified. These nine renewal modes are feasible to guide the redevelopment of Harbin in the future to a considerable extent. Moreover, the regions in modes 1-4 need to focus on the lack of green space. Modes 1-8 need to focus on the balance of urban functions and transportation in future construction.

\section{Conclusions}

The imbalance in urban resource allocation is inevitable and is mainly reflected when developing transportation infrastructure and the corresponding urban functional facilities during urban renewal. The refined evaluation indexes of urban green space incorporated into the node-place models are prone to widen the decision-making dimension of sustainable urban renewal mode. Moreover, combination of transportation, land use, and ecological construction could identify the development stage of sustainable urban renewal more scientifically. In this study, we use U-Net to identify the urban green space (low vegetation and trees) in Harbin. The ratio of vegetation to the region reveals and measures the environmental index of the corresponding region, which ensures the refinement of urban feature recognition. Secondly, we expanded the node-place model, using those green indicators as the third dimension to jointly measure the state of urban construction, which dynamically monitors the sustainable renewal status. Since then, we separately analyzed the development status of urban functions, transportation, and green space in Harbin. Finally, we identified the state of the urban construction in Harbin and proposed a future sustainable development model for transportation, urban function, and ecological construction. We find that there is a large gap in the place value in various regions of Harbin, and the overall development in urban function lags behind that of transportation and green space. Furthermore, regions in northern and southwest Harbin have potential for renewal. Based on the place value, node value, and green value, nine sustainable urban renewal modes are identified. Although three dimensions of urban development imbalance are introduced in this work, the proposed method still has limitations. This study does not incorporate population movement data as well as the scenario simulation. In future research, we plan to explore a more comprehensive spatiotemporal analysis on the urban development imbalance. Such a study would provide more specific guidelines for sustainable urban renewal.

\section{Data Availability}

The data used to support the findings of this study are included within the article.

\section{Conflicts of Interest}

The authors declare that there are no conflicts of interest regarding the publication of this paper.

\section{Authors' Contributions}

Rong Guo and Xiaoya Song contributed equally to this work.

\section{Acknowledgments}

This work was supported by the Japan Society for the Promotion of Science (JSPS).

\section{References}

[1] H. Zhang, X. Song, Y. Long et al., "Mobile phone GPS data in urban bicycle-sharing: layout optimization and emissions reduction analysis," Applied Energy, vol. 242, pp. 138-147, 2019.

[2] Y. Long, Y. Yoshida, K. Fang, H. Zhang, and M. Dhondt, "City-level household carbon footprint from purchaser point of view by a modified input-output model," Applied Energy, vol. 236, pp. 379-387, 2019.

[3] E. Zarghami and D. Fatourehchi, "Comparative analysis of rating systems in developing and developed countries: a systematic review and a future agenda towards a region-based sustainability assessment," Journal of Cleaner Production, vol. 254, Article ID 120024, 2020.

[4] S. Yildiz, S. Kivrak, and G. Arslan, "Contribution of built environment design elements to the sustainability of urban renewal projects: model proposal," Journal of Urban Planning and Development, vol. 145, no. 1, Article ID 04018045, 2019.

[5] C. Hachem, "Impact of neighborhood design on energy performance and GHG emissions," Applied Energy, vol. 177, pp. 422-434, 2016.

[6] Y. Long, Y. Yoshida, Q. Liu, H. Zhang, S. Wang, and K. Fang, "Comparison of city-level carbon footprint evaluation by applying single- and multi-regional input-output tables," Journal of Environmental Management, vol. 260, Article ID 110108, 2020.

[7] V. Bansal, S. Bansal, and J. Sen, “Assessing the role of urban design in a rapidly urbanizing historical city and its contribution in restoring its urban ecology: the case of Varanasi, India," Urban Ecology, pp. 413-434, 2020.

[8] X. Song, R. Guo, T. Xia et al., "Mining urban sustainable performance: millions of GPS data reveal high-emission travel attraction in Tokyo," Journal of Cleaner Production, vol. 242, Article ID 118396, 2020.

[9] Y. Wang, J. Li, G. Zhang, Y. Li, and M. H. Asare, "Fuzzy evaluation of comprehensive benefit in urban renewal based on the perspective of core stakeholders," Habitat International, vol. 66, pp. 163-170, 2017. 
[10] X. Li, E. C. M. Hui, T. Chen, W. Lang, and Y. Guo, "From Habitat III to the new urbanization agenda in China: seeing through the practices of the "three old renewals" in Guangzhou," Land Use Policy, vol. 81, pp. 513-522, 2019.

[11] Y. Long, Y. Yoshida, J. Meng, D. Guan, L. Yao, and H. Zhang, "Unequal age-based household emission and its monthly variation embodied in energy consumption-a cases study of Tokyo, Japan," Applied Energy, vol. 247, pp. 350-362, 2019.

[12] G. Liu, L. Wei, J. Gu, T. Zhou, and Y. Liu, "Benefit distribution in urban renewal from the perspectives of efficiency and fairness: a game theoretical model and the government's role in China," Cities, vol. 96, Article ID 102422, 2020.

[13] R. C. Estoque and M. Ooba, X. T. Seposo, Heat health risk assessment in Philippine cities using remotely sensed data and social-ecological indicators," Nature Communications, vol. 11, no. 1, pp. 1-12, 2020.

[14] L. W. C. Lai and F. T. Lorne, "Sustainable urban renewal and built heritage conservation in a global real estate revolution," Sustainability, vol. 11, no. 3, p. 850, 2019.

[15] Z. Qiao, L. Liu, Y. Qin, X. Xu, B. Wang, and Z. Liu, “The impact of urban renewal on land surface temperature changes: a case study in the main city of Guangzhou, China," Remote Sensing, vol. 12, no. 5, p. 794, 2020.

[16] Q. Yu, H. Zhang, W. Li et al., "Mobile phone data in urban bicycle-sharing: market-oriented sub-area division and spatial analysis on emission reduction potentials," Journal of Cleaner Production, vol. 254, Article ID 119974, 2020.

[17] Y. Peng, J. Qian, F. Ren, W. Zhang, and Q. Du, "Sustainability of land use promoted by construction-to-ecological land conversion: a case study of Shenzhen city, China," Sustainability, vol. 8, no. 7, p. 671, 2016.

[18] H. Leng, X. Chen, Y. Ma, N. H. Wong, and T. Ming, "Urban morphology and building heating energy consumption: evidence from Harbin, a severe cold region city," Energy and Buildings, vol. 224, Article ID 110143, 2020.

[19] H. Leng, S. Li, S. Yan, and X. An, "Exploring the relationship between green space in a neighbourhood and cardiovascular health in the winter city of China: a study using a health survey for harbin," International Journal of Environmental Research and Public Health, vol. 17, no. 2, p. 513, 2020.

[20] T. Zhou, Y. Zhou, and G. Liu, "Key variables for decisionmaking on urban renewal in China: a case study of Chongqing," Sustainability, vol. 9, no. 3, p. 370, 2017.

[21] J. A. Adedeji and O. Arayela, "Urban renewal strategies and economic growth in Ondo State, Nigeria: a case study," Journal of Contemporary Urban Affairs (JCUA), vol. 2, no. 1, pp. 76-83, 2017.

[22] L. Bertolini, "Spatial development patterns and public transport: the application of an analytical model in The Netherlands," Planning Practice and Research, vol. 14, no. 2, pp. 199-210, 1999.

[23] Y. Zhang, S. Marshall, and E. Manley, "Network criticality and the node-place-design model: classifying metro station areas in Greater London," Journal of Transport Geography, vol. 79, p. 102485, 2019.

[24] R. Falconer, C. Babb, and D. Olaru, "Cities as systems: node and place conflict across a rail transit network," "Cities as systems: node and place conflict across a rail transit network," in Planning Boomtown and Beyond, S. Biermann, D. Olaru, and V. Paül, Eds., pp. 446-475, UWA Publishing, Perth, WA, USA, 2016.

[25] P. Pezeshknejad, S. Monajem, and H. Mozafari, "Evaluating sustainability and land use integration of BRT stations via extended node place model, an application on BRT stations of
Tehran," Journal of Transport Geography, vol. 82, Article ID 102626, 2020.

[26] F. Caset, D. S. Vale, and C. M. Viana, "Measuring the accessibility of railway stations in the Brussels Regional Express Network: a node-place modeling approach," Networks and Spatial Economics, vol. 18, no. 3, pp. 495-530, 2018.

[27] D. Olaru, S. Moncrieff, G. McCarney et al., "Place vs. node transit: planning policies revisited," Sustainability, vol. 11, no. 2, p. 477, 2019.

[28] P. Chorus and L. Bertolini, "An application of the node place model to explore the spatial development dynamics of station areas in Tokyo," Journal of Transport and Land Use, vol. 4, no. 1, pp. 45-58, 2011.

[29] D. S. Vale, "Transit-oriented development, integration of land use and transport, and pedestrian accessibility: combining node-place model with pedestrian shed ratio to evaluate and classify station areas in Lisbon," Journal of Transport Geography, vol. 45, pp. 70-80, 2015.

[30] Z. Li, Z. Han, J. Xin, X. Luo, S. Su, and M. Weng, “Transit oriented development among metro station areas in Shanghai, China: variations, typology, optimization and implications for land use planning," Land Use Policy, vol. 82, pp. 269-282, 2019.

[31] D. S. Vale, C. M. Viana, and M. Pereira, "The extended nodeplace model at the local scale: evaluating the integration of land use and transport for Lisbon's subway network," Journal of Transport Geography, vol. 69, pp. 282-293, 2018.

[32] B. Höfle, M. Hollaus, and J. Hagenauer, "Urban vegetation detection using radiometrically calibrated small-footprint full-waveform airborne LiDAR data," ISPRS Journal of Photogrammetry and Remote Sensing, vol. 67, pp. 134-147, 2012.

[33] M. Nixon and A. S. Aguado, Feature Extraction and Image Processing for Computer Vision, Academic Press, Cambridge, MA, USA, 2019.

[34] E. Alpaydin, Introduction to Machine Learning, MIT press, Cambridge, MA, USA, 2020.

[35] C. J. Tucker, J. E. Pinzon, M. E. Brown et al., "An extended AVHRR 8-km NDVI dataset compatible with MODIS and SPOT vegetation NDVI data," International Journal of Remote Sensing, vol. 26, no. 20, pp. 4485-4498, 2005.

[36] G. M. Gandhi, S. Parthiban, N. Thummalu, and A. Christy, "Ndvi: vegetation change detection using remote sensing and Gis-a case study of Vellore district," Procedia Computer Science, vol. 57, pp. 1199-1210, 2015.

[37] Q. Wang and J. D. Tenhunen, "Vegetation mapping with multitemporal NDVI in North Eastern China transect (NECT)," International Journal of Applied Earth Observation and Geoinformation, vol. 6, no. 1, pp. 17-31, 2004.

[38] R. Geerken, B. Zaitchik, and J. P. Evans, "Classifying rangeland vegetation type and coverage from NDVI time series using Fourier Filtered Cycle Similarity," International Journal of Remote Sensing, vol. 26, no. 24, pp. 5535-5554, 2005.

[39] F. Rottensteiner, G. Sohn, J. Jung et al., "The ISPRS benchmark on urban object classification and 3D building reconstruction," ISPRS Annals of Photogrammetry, Remote Sensing and Spatial Information Sciences, vol. I-3, no. 1, pp. 293-298, 2012.

[40] Q. Chen, L. Wang, Y. Wu, G. Wu, Z. Guo, and S. L. Waslander, "Aerial imagery for roof segmentation: a large-scale dataset towards automatic mapping of buildings," 2018, https://arxiv.org/abs/1807.09532.

[41] I. Goodfellow, Y. Bengio, and A. Courville, Deep Learning, MIT press, Cambridge, MA, USA, 2016. 
[42] Z. Guo, G. Wu, X. Song et al., "Super-resolution integrated building semantic segmentation for multi-source remote sensing imagery," IEEE Access, vol. 7, pp. 99381-99397, 2019.

[43] G. Wu, Y. Guo, X. Song et al., "A stacked fully convolutional networks with feature alignment framework for multi-label land-cover segmentation," Remote Sensing, vol. 11, no. 9, p. 1051, 2019.

[44] C. Iovan, D. Boldo, M. Cord, and M. Erikson, "Automatic extraction and classification of vegetation areas from high resolution images in urban areas," in Proceedings of the Scandinavian Conference on Image Analysis, pp. 858-867, Springer, Aalborg, Denmark, June 2007.

[45] O. Ronneberger, P. Fischer, and T. Brox, "U-net: convolutional networks for biomedical image segmentation," in Proceedings of the International Conference on Medical image computing and computer-assisted, pp. 234-241, Munich, Germany, October 2015.

[46] X. Zhang, Y. Zou, and W. Shi, "Dilated convolution neural network with LeakyReLU for environmental sound classification," in Proceedings of the 2017 22nd International Conference on Digital Signal Processing (DSP), IEEE, London, UK, pp. 1-5, August 2017.

[47] S. Ioffe and C. Szegedy, "Batch normalization: accelerating deep network training by reducing internal covariate shift," 2015, https://arxiv.org/abs/1502.03167.

[48] H. Peng, J. Li, Y. Song, and Y. Liu, "Incrementally learning the hierarchical softmax function for neural language models," in Proceedings of the Thirty-First AAAI Conference on Artificial Intelligence, San Francisco, CF, USA, February 2017. 